\title{
Shaking Table Tests and Validation of Multi-Modal Sensing and Damage Detection Using Smartphones
}

\author{
Ruicong Han ${ }^{1}$ and Xuefeng Zhao ${ }^{2,3, *}$ \\ 1 School of Civil Engineering and Communication, North China University of Water Resources and Electric \\ Power, Zhengzhou 450045, China; hanruicong@ncwu.edu.cn \\ 2 State Key Laboratory of Coastal and Offshore Engineering, Dalian University of Technology, \\ Dalian 116023, China \\ 3 School of Civil Engineering, Dalian University of Technology, Dalian 116023, China \\ * Correspondence: zhaoxf@dlut.edu.cn
}

Citation: Han, R.; Zhao, X. Shaking Table Tests and Validation of Multi-Modal Sensing and Damage Detection Using Smartphones. Buildings 2021, 11, 477. https:// doi.org/10.3390/buildings11100477

Academic Editor: Nerio Tullini

Received: 7 September 2021

Accepted: 12 October 2021

Published: 14 October 2021

Publisher's Note: MDPI stays neutral with regard to jurisdictional claims in published maps and institutional affiliations.

Copyright: (c) 2021 by the authors. Licensee MDPI, Basel, Switzerland. This article is an open access article distributed under the terms and conditions of the Creative Commons Attribution (CC BY) license (https:// creativecommons.org/licenses/by/ $4.0 /)$.

\begin{abstract}
Structural health monitoring (SHM) systems using modal- and vibration-based methods, particularly wireless systems, have been widely investigated in relation to the monitoring of damage states in civil infrastructures such as bridges and buildings. Unlike many current efforts in developing wireless sensors, one can instead leverage the suite of sensors, network transmission, data storage, and embedded processing capabilities built into modern smartphones for SHM. The objective of this work was to assess and validate the use of smartphones for the monitoring of artificial damage states in a three-story steel frame model subjected to shaking table-induced earthquake excitations. The steel frame was a 2D structure with six rotary viscous dampers installed at the beam-column joints, which were used for simulating different damage states at their respective locations; the columns were also replaced with ones of reduced cross-sectional areas to further emulate damage. In addition to instrumenting the frame with conventional tethered sensors, Apple iPhones (pre-loaded with customized smartphone apps to record acceleration and inter-story displacement) were also installed. Shaking table tests were then conducted on the undamaged and damaged frames, while conventional sensors' and smartphones' responses were collected and compared. Wavelet packet decomposition was employed to analyze the acceleration data to detect damage in two different cases. Structural displacements were also computed from acceleration measurements and compared with displacement measurements to further validate the quality of smartphone sensor measurements.
\end{abstract}

Keywords: smartphone; damage detection; monitoring; shaking table tests; buildings; steel frame; wavelet packet; frequency-domain integration

\section{Introduction}

Extreme events such as earthquakes can cause severe damage to structures, and an event can occur at any time during the structure's operating service lifetime $[1,2]$. For example, the 2011 Christchurch earthquake caused $\sim 11$ to 15 billion US dollars in economic losses [3,4]. Another example is the 2011 Tohoku earthquake, which caused nearly 30,000 casualties [2] and 195 billion US dollars in losses. Similarly, the 2010 Haiti and 2008 Wenchuan earthquakes also led to massive casualties (i.e., 27,000 [5] and 69,000 [6], respectively). Hence, the assessment of structural performance, before, during, and after an extreme event, is critical for ensuring their safe operations and resiliency to natural hazards such as earthquakes.

In that regard, structural health monitoring (SHM) aims to achieve this goal by integrating sensors, structural response measurements, and algorithms to detect and localize damage. Damage information can not only help inform decisions for repairs but also facilitate urban planning and post-earthquake emergency rescue efforts [7]. Maintaining civil infrastructure systems' optimal performance is necessary for preventing structural 
failure, which can reduce the number of casualties and property losses incurred following an extreme event.

SHM using vibration measurements have seen tremendous advancements over the last few decades [8]. The principle of modal analysis is that modal parameters are functions of the physical properties of the structure (i.e., mass, damping, and stiffness), which can be determined using acceleration response time history measurements [9]. Peeters and De Roeck [10] reviewed system identification methods for operational modal analysis, such as using the complex mode identification function [11], the instrumental-variable method [12], and stochastic subspace identification $[13,14]$, among others, and their accuracies in terms of identifying modal parameters were compared by means of a Monte-Carlo analysis. Hearn et al. [15] demonstrated a structural inspection method based on modal analysis of vibration response in experiments on a welded steel frame and on wire rope. Lam et al. [16] conducted a full-scale ambient vibration test of a 14-story reinforced concrete building, where six horizontal vibration modes were identified with Bayesian modal analysis and Markov Chain Monte Carlo-based model updating and when using only limited numbers of sensor measurements. Worden and Green [17] proposed a machine learning approach for nonlinear modal analysis and demonstrated their applicability using a number of case studies based on both simulated and experimental acceleration data. Mirshafiei et al. [18] introduced an approach for seismic assessment based on experimental modal analysis using acceleration and velocity measurements. The technique was verified using four buildings located in Montreal, Canada.

On the other hand, displacement is another particularly important parameter when nonlinear behavior and permanent deformations occur [19]. Traditionally, displacements are measured using linear potentiometers and linear variable differential transducers (LVDTs). However, they measure relative displacements and require a fixed reference point, which is often unavailable. One solution is to construct a scaffold underneath the point of interest and use the ground as a stationary reference. This is often impractical because of costs and considerable time required for field assembly and disassembly of the scaffold [20]. It should be mentioned that acceleration data can be double integrated to obtain displacements. Unfortunately, the results are typically erroneous, with large drifts observed. Frequency-domain integration methods can also be used, but errors are introduced due to the low-cut-off frequency, and multiple attempts are needed to identify an optimal frequency range [21]. Despite these limitations, displacement and acceleration data can be used to compute damage indices for SHM purposes $[15,22]$.

In fact, a variety of different monitoring systems have been implemented in large-scale structures. In the case of bridges, although tethered monitoring systems have been widely used in the past [23], the field is transitioning towards the use of wireless sensor networks so as to avoid the difficulties, high-costs, and degradation issues associated with cables [24-27]. Wireless sensors' node-to-node communications in this application are suitable since they operate in an open space environment. Different types of sensors can often be interfaced with these wireless sensor nodes to realize both acceleration, displacement, temperature, and wind speed monitoring, among many other parameters. However, wireless signals can be obstructed by walls and partitions in a building, causing signal reliability issues [28,29], which make their use in high-rises more difficult. Therefore, there remains a need to develop rapid, low-cost, and convenient monitoring techniques for structural response monitoring and rapid damage evaluation.

Recent advances in smartphones offer a unique opportunity for SHM [30], since these devices host a suite of different sensors, multi-modal wireless communication capabilities, and computing power, all packaged in a small form factor. In fact, smartphones have been used for various applications, such as for human monitoring [31], movement recognition [32], and car accident detection [33]. Yu and Zhao [34] proposed the concept for SHM using smartphones in civil infrastructures, and they have also been investigated, in the laboratory and field, for SHM of civil infrastructure systems [34-54]. Höpfner and Morgenthal $[35,36]$ studied the possibilities and limitations of using smartphones for the 
measurement of mechanical oscillations and transient structural displacements. Reilly et al. [38] developed a mobile app, iShake, to use smartphones as seismographs to measure and then transmit ground motion data to a central server. The accuracy of the built-in sensors was validated through shaking table tests. Sharma and Gupta [39] measured various field parameters, including absolute location with GPS (in terms of latitude and longitude), distance, area, and perimeter, using an Android app called MAP MEASURE. Cimellaro et al. [40] proposed a rapid building damage assessment system using mobile phone technology, which can collect photos of damaged houses with the help of residents or volunteers situated in disaster-struck areas. Feng et al. [42] and Ozer et al. [43] developed a crowdsourcing platform for SHM and a post-event damage assessment app. Min et al. [44] developed a smartphone application called RIRO to measure absolute dynamic displacements by processing image frames of a color-patterned target. Oraczewski and Staszewski [45] developed a platform for crack detection based on nonlinear acoustics and validated the system using a simple example of fatigue crack detection in aluminum plates. Ozer and Feng [46] proposed a modal identification strategy that integrated spatial and temporally sparse SHM data collected from smartphones. In addition, Ozer and Feng [47] also proposed a coordinate system transformation procedure to correct the sensor signal caused by the improper positioning of smartphone sensors, followed by its validation using impact hammer testing conducted on a two-story laboratory structural model and a real bridge. Xie et al. [54] conducted a single-layer frame test and the frame responses were measured by using smartphones.

It is clear from the aforementioned studies that SHM research based on smartphones has been developing at a rapid pace with contributions from various countries. These studies were mostly validated in the laboratory, and a significant amount of attention was on bridge monitoring, ground motion monitoring, measurement uncertainties, and postdisaster investigation. Their applications for SHM and damage detection during an event (e.g., an earthquake), particularly in multi-story buildings and frames, remains limited and is a main focus of this study. Moreover, the displacement obtained by smartphone acceleration signals in multi-story buildings has not been studied previously.

In this work, the objective was to assess and validate the use of smartphones in relation to the monitoring of artificial damage states, by measuring acceleration and inter-story displacements, in a three-story steel frame structure subjected to shaking table-induced earthquake excitations. This paper begins with a discussion of the experimental details, including the test structure, test plan, and damage cases. Second, and upon conducting the tests, smartphone monitoring capabilities were validated by comparing measured responses (of undamaged and two damaged cases) to those obtained by conventional sensors. Third, wavelet packet analysis was employed for damage detection and for computing a suitable damage index based on energy ratio variation difference (ERVD). Lastly, as further validation, frequency-domain integration converted raw acceleration signals to displacements, which was also used for comparison purposes.

\section{Experimental Details}

\subsection{Test Structure}

The testbed employed in this study was a planar, three-story, steel frame with six viscous dampers installed at the beam-column joints (Figure 1). Each story was $400 \mathrm{~mm}$ tall, and the width of the frame was $500 \mathrm{~mm}$. Each floor consisted of two parts, namely, the deck (which houses weights) and a removable beam (highlighted by the blue boxes shown in Figure 1). The beams were thick steel plates and were considered to be axially and flexurally rigid. On the other hand, the columns were $4 \mathrm{~mm}$-thick, $150 \mathrm{~mm}$-wide, and $400 \mathrm{~mm}$-tall steel plates. The beams and columns were connected by viscous dampers that were $180 \mathrm{~mm}$ in height. The test structure was bolted onto a dual-axis Quanser XY Shake Table III that could support and excite loads of up to $100 \mathrm{~kg}$. The shake table was produced by the Canadian company QUANSER. The vibration amplitude reached $20 \mathrm{~cm}$ in one or two directions. It was driven by a linear motor, so the number of vibration parts 
was minimized, which effectively increased the reliability of the vibration and minimized the noise of the vibration. The shake table could apply a variety of excitations, such as earthquake wave, sine wave, artificial wave, etc.

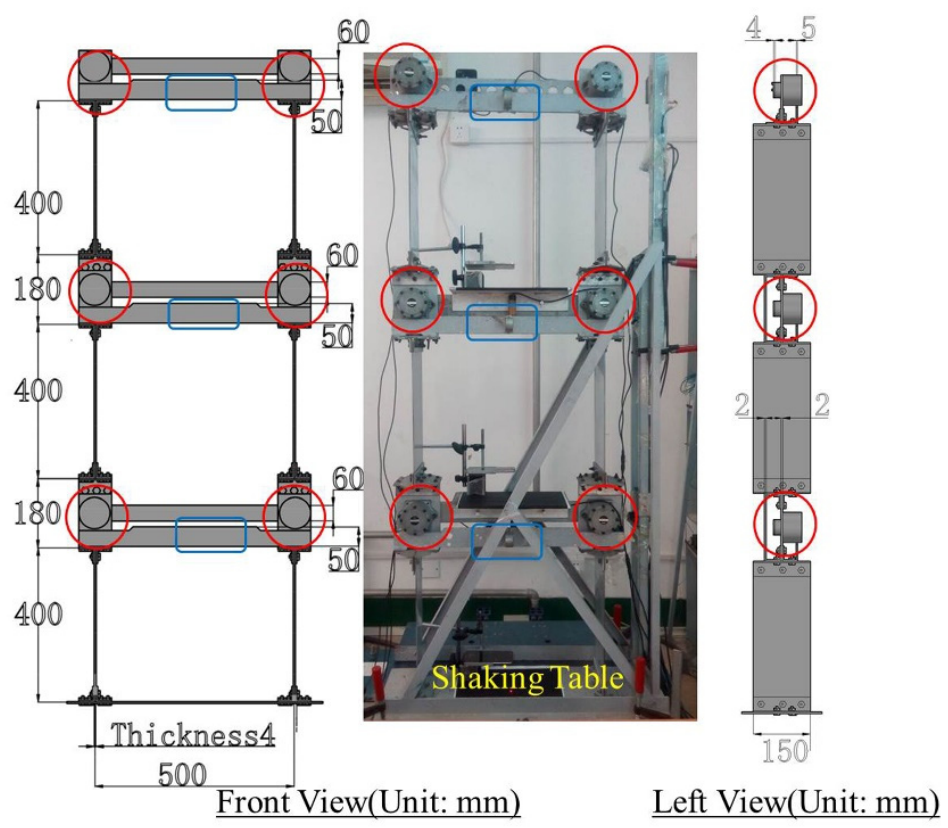

Figure 1. Illustrations and a picture of the three-story steel frame tested are shown. Viscous dampers are circled in red, and the removable rigid beams are boxed in blue.

The six rotary viscous dampers, which were installed at the beam-column joints and marked in red, are shown in Figure 1. With the beams installed, the rotary dampers did not contribute to the frame's response. However, once the beams were removed, the dampers allowed one to introduce artificial damage to the frame by simply turning the notch to different positions. In its initial and undamaged state, the rigid beams emulated a fixed-fixed beam-column connection. When the rigid beam (i.e., that which is marked by blue boxes in Figure 1) was removed, and the damper notch was rotated clockwise to different positions, damping could be gradually increased. The increased damping at the joints simulated nonlinear structural behavior and damage in the system (i.e., without having to physically damage the test structure). On the other hand, the columns were connected with beams by screws, so the intact columns could be replaced by damaged columns with reduced cross-sectional areas; in this case, the structure consisted of fixedfixed beam-column connections with the removable beam installed to introduce minor artificial damage.

\subsection{Instrumentation Layout}

The experimental setup is shown in Figure 2. Both conventional cabled monitoring systems and smartphones were instrumented onto the test structure to measure the structural responses during testing. First, three Sinocera Piezotronics uniaxial piezoelectric accelerometers (PA) were instrumented on the structure (i.e., one on each floor) and connected to a data acquisition (DAQ) system. The sensitivity of the accelerometer was $500 \mathrm{mV} / \mathrm{g}$ with a maximum output voltage of $6 \mathrm{~V}$ and it required -12 to $+24 \mathrm{~V}$ direct current (DC) power. Second, a separate DAQ system was employed for acquiring displacement measurements from three Keyence KL-300 laser displacement sensors (LDS) (i.e., one on each floor). Each LDS measured the absolute displacement of each floor; this was achieved by attaching the LDS to a separate triangular support that was located outside the frame (but still bolted to the shaking table) and positioned at the same height as each floor. They each projected a laser beam onto a magnetic bearing mounted onto a customized suspended 
frame connected to each floor. The measurement range of the LDS was 160 to $450 \mathrm{~mm}$ with an output voltage of 0 to $5 \mathrm{~V}$. It should be noted that both DAQ systems featured $100 \mathrm{~dB}$ dynamic range and 24-bit analog-to-digital converters (ADC), and the systems were connected to laptop computers for system control and data storage.

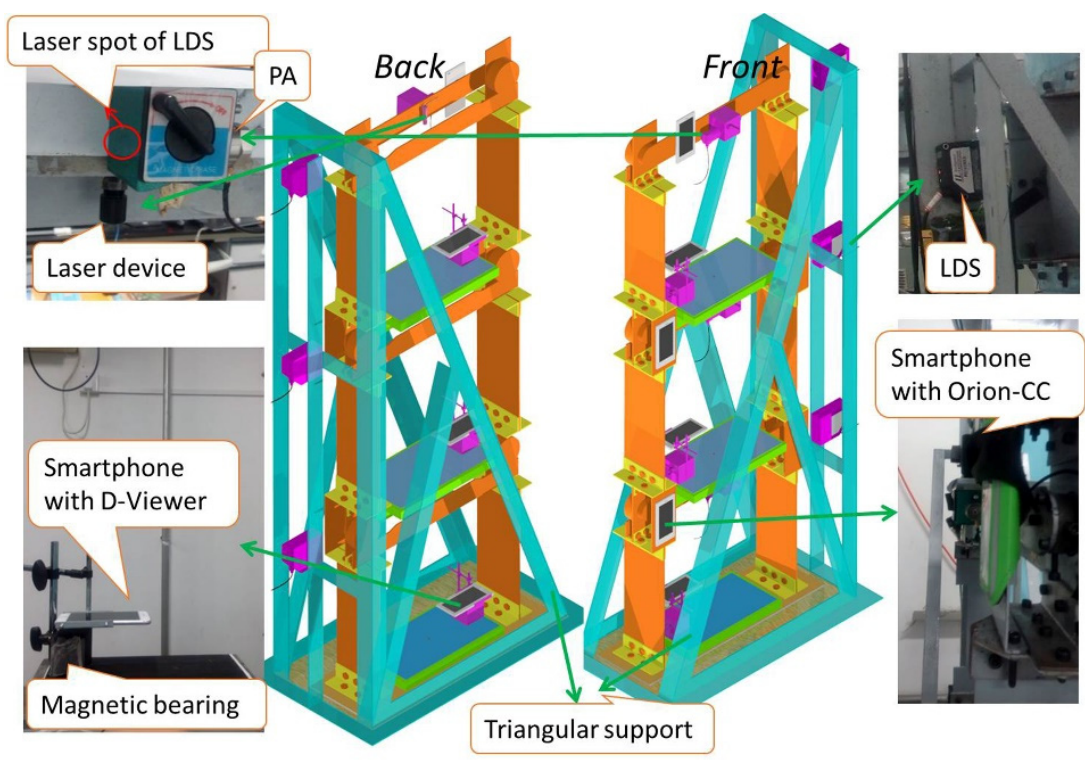

Figure 2. The various sensors instrumented in different locations in the steel frame testbed are shown.

In addition to the aforementioned accelerometers and LDS, six Apple iPhones were also installed on the steel frame. Three of the smartphones were for recording the acceleration response of the structure, while the remaining three were for acquiring inter-story displacements. First, an iPhone 6, iPhone 5s, and iPhone 4s were placed on the first, second, and third story of the steel frame, respectively. Smartphones house a plethora of built-in sensors, along with storage, network connection, and computing power, but access to these features requires suitable software apps being installed. To that end, previous studies culminated in the development of two smartphone apps, namely Orion-CC [52] and D-Viewer [53], specifically for SHM. Here, the phones, preloaded with Orion-CC [52], were installed alongside the PAs (installed on magnetic bearings), so that both the uniaxial accelerometers and one axis of measurement of the smartphone's internal accelerometer were aligned with the direction of vibration. It should be mentioned that Orion-CC can access Apple iPhone's internal accelerometer and gyroscope and store data as commanded by the user. The mobile app was built for an iOS 7.0 or higher platform. Both the PAs and smartphones recorded acceleration using a sampling rate of $100 \mathrm{~Hz}$. However, the actual sampling rates of the smartphones varied due to different built-in sensor performances and the different platforms; from the collected data, it was found that the actual sampling rates of the iPhone $6,5 \mathrm{~s}$, and $4 \mathrm{~s}$ were 100,96 , and $109 \mathrm{~Hz}$, respectively.

Second, three iPhone 6, preloaded with D-Viewer [53], were installed on the test structure to measure inter-story displacements. D-Viewer is an app (for both the iOS and Android platforms) that is used for the monitoring of dynamic displacements by using the built-in camera to recognize and track a moving laser or black circle (i.e., target) so as to determine relative displacements. In this study, a laser pointer was installed on the beam of each floor and projected a laser spot, downwards, onto a flat plate that was mounted above the lower story of the frame. In this manner, the laser source and smartphone would remain static relative to the floor moving above, and relative displacements could be computed by tracking the motion of the laser spot projected onto the plate. While the LDS displacement data were recorded at $100 \mathrm{~Hz}$, the sampling rates of the smartphones were limited by the sampling rate of video recorded, which, in this case, was 30 frames per second or $30 \mathrm{~Hz}$. 
It should be mentioned that both Orion-CC and D-Viewer are publicly available and are described in greater detail in Zhao et al. [52,53].

\subsection{Test Plan and Damage Cases}

Three cases were considered in this study. The first was the undamaged case, where all of the viscous dampers were configured in their initial positions, and the beam-column connections were considered rigid with the rigid beam installed on each floor (Figure 3a). The second was the damaged case \#1 (Figure 3b), where one column in the first floor was reduced by $30 \%$. The third was the damaged case \#2 (Figure 3d), where the rigid beam in the first floor was removed, while the columns were intact. By removing the rigid beam, the viscous dampers could begin to affect structural response (Figure 3b). For all three cases, the shaking table excited the steel frame using the El-Centro earthquake ground motion (i.e., scaled to $20 \mathrm{~mm}$ peak ground displacement). The response of the structure was monitored by the instrumented sensors and smartphones.

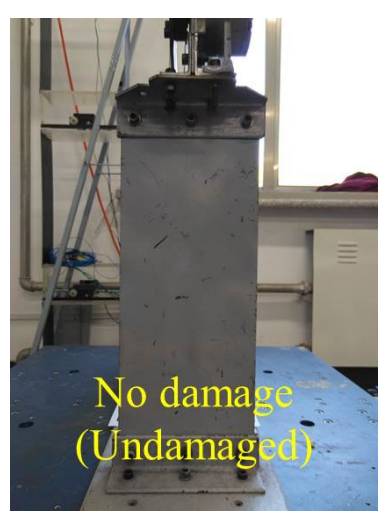

(a)

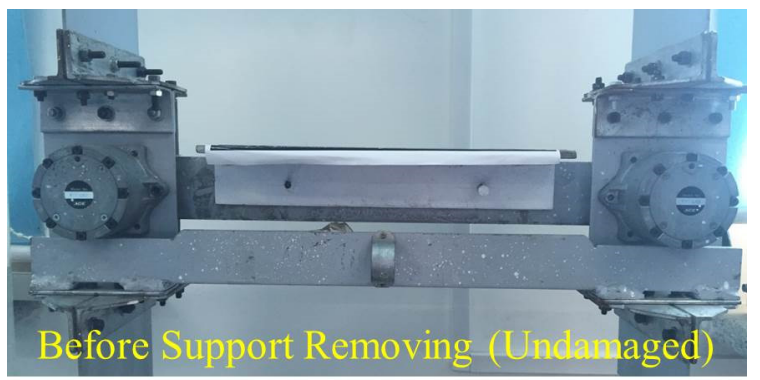

(c)

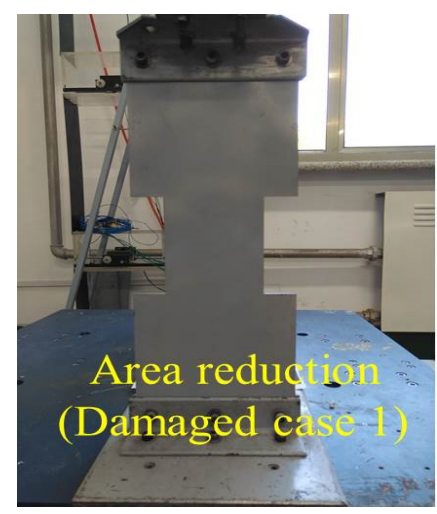

(b)

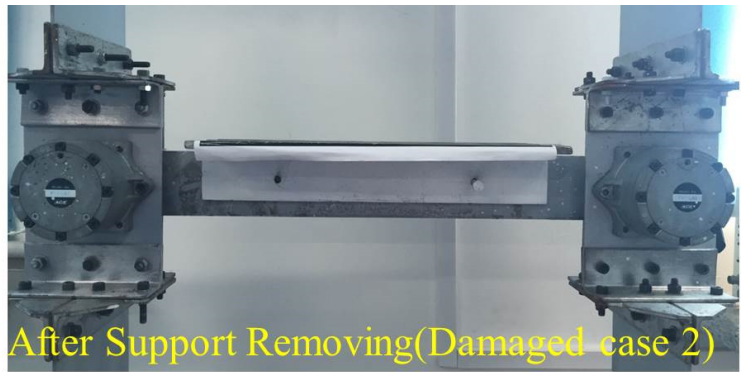

(d)

Figure 3. The pictures show the (a) undamaged steel frame; (b) damaged case 1 with a reduction in the area of the column; (c) undamaged frame, the same as that shown in (a); (d) damaged case 2, with the rigid beam removed from the first floor.

\section{Steel Frame Response Comparison}

\subsection{Acceleration Response}

Upon conducting the shaking table tests, the acceleration (a) time history responses from the tethered PAs and smartphones were compared. Figure 4 overlays representative sets of results of each floor, including the undamaged case and two damaged cases. In order to better visualize the similarities and differences in the data, only $2 \mathrm{~s}$ of the recorded time histories were presented. It can be observed from Figure 4 that the time history results matched one another closely. By taking a fast Fourier transform of the time-domain data, the corresponding power spectral density (PSD) (logarithmic scale) functions corresponding to the cases shown in Figure 4 were obtained and are presented in Figure 5. It can be seen that, while the frequency-domain results matched closely for all cases, some differences were observed for the damaged scenarios. It was more likely that differences in sensors 
(i.e., built in different iPhone models) was the primary factor that caused this error. A more in-depth error analysis will be discussed in Section 5.2.1, but these results suggest that smartphones can be used for vibration monitoring.

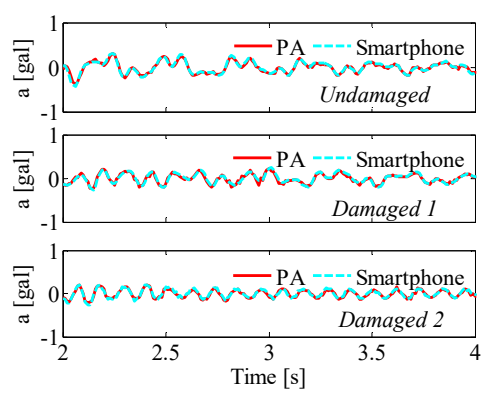

(a)

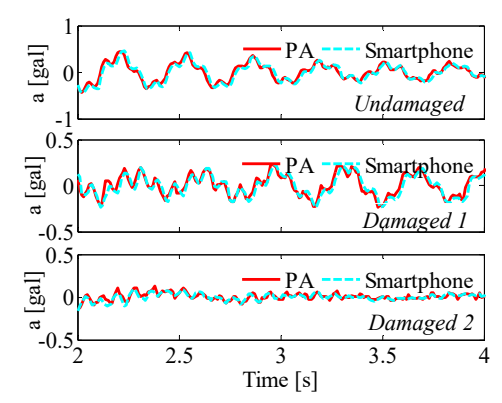

(b)

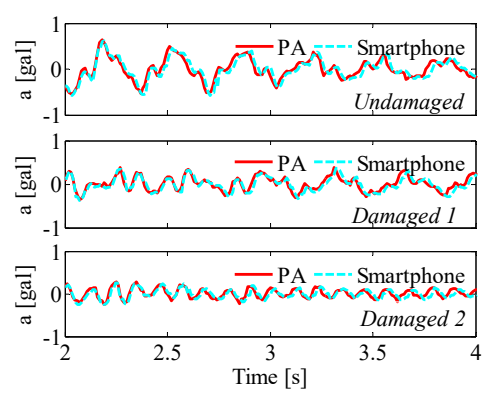

(c)

Figure 4. The acceleration time history responses as collected by the tethered PAs and smartphones, for both undamaged and two damaged cases, were compared to show good agreement. Representative results from the (a) first, (b) second, and (c) third floors were overlaid.

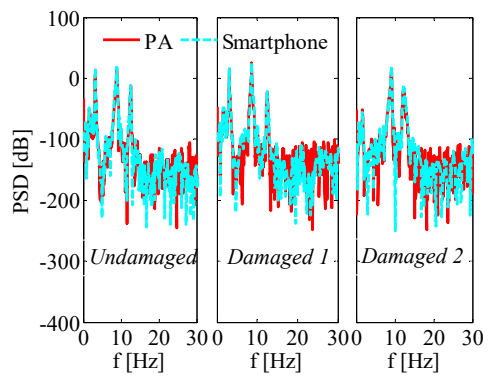

(a)

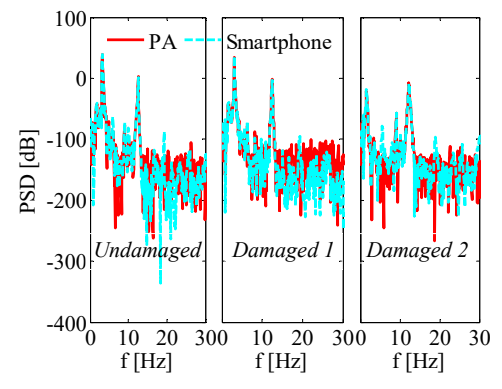

(b)

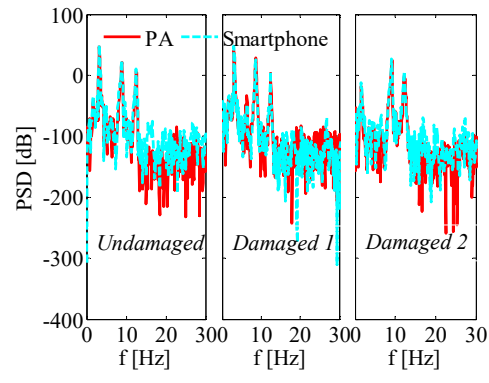

(c)

Figure 5. Using acceleration time history measurements from Figure 4, the power spectral density functions for the (a) first, (b) second, and (c) third floors were computed and plotted.

Regardless, the first, second and third modal frequencies of the structure were obtained by processing the results shown in Figure 5 using a peak-picking algorithm. Table 1 summarizes the modal frequencies identified with the time-histories of each floor. The second modal frequency in damaged case \#1 was difficult to identify using the data of the second floor, since the sensors were installed at the node of the second vibration mode. From Table 1, it can be seen that the reductions in the modal frequencies for damaged case \#1 were not significant, since damage was not severe in this case. However, for damaged case \#2, the reduction in the first modal frequency was significant, since the removal of the rigid beam reduced the overall stiffness of the structure. Except for the first modal frequency variation, the increase in the second modal frequency and the reduction in the third modal frequency were insignificant. The differences in modal frequencies, as identified by the tethered system versus the smartphones, were nearly negligible. Therefore, the smartphone can be a tool to capture signals for damaged cases. This is the first step in the use of smartphones in a frame model; further research will focus on the frequency identification method using smartphone signals. 
Table 1. Modal frequency results obtained using the tethered PA and smartphones.

\begin{tabular}{|c|c|c|c|c|c|c|c|}
\hline \multirow{2}{*}{ Story } & \multirow{2}{*}{ Damage Cases } & \multicolumn{2}{|c|}{ First Modal (Hz) } & \multicolumn{2}{|c|}{ Second Modal (Hz) } & \multicolumn{2}{|c|}{ Third Modal (Hz) } \\
\hline & & Tethered PA & Smartphone & Tethered PA & Smartphone & Tethered PA & Smartphone \\
\hline \multirow{4}{*}{ First floor } & Undamaged & 3.182 & 3.182 & 8.9 & 8.9 & 12.6 & 12.5 \\
\hline & Damage \#1 & 3 & 3 & 8.7 & 8.7 & 12.4 & 12.4 \\
\hline & Damage \#2 & 1.545 & 1.545 & 9.2 & 9.1 & 12.2 & 12.2 \\
\hline & Undamaged & 3.182 & 3.182 & 8.9 & 9.0 & 12.5 & 12.6 \\
\hline \multirow{2}{*}{ Second floor } & Damage \#1 & 3 & 3 & - & - & 12.4 & 12.4 \\
\hline & Damage \#2 & 1.545 & 1.545 & 9.2 & 9.2 & 12.2 & 12.3 \\
\hline \multirow{3}{*}{ Third floor } & Undamaged & 3.182 & 3.182 & 8.9 & 8.9 & 12.5 & 12.5 \\
\hline & Damage \#1 & 3 & 3 & 8.7 & 8.6 & 12.41 & 12.4 \\
\hline & Damage \#2 & 1.545 & 1.545 & 9.1 & 9.1 & 12.2 & 12.2 \\
\hline
\end{tabular}

\subsection{Displacement Response}

According to Section 2.2, inter-story displacements were obtained using an image processing scheme using video recorded by the smartphones, and reference displacement measurements were collected using LDS instrumented at each floor. Representative sets of displacement measurements were compared, for the undamaged and two damaged cases, and the results are overlaid in Figure 6. It should be noted that the inter-story displacement of the $i$ th story, as measured by the LDS, was computed by subtracting the LDS data of the $(i-1)$ th story from the $i$ th story (i.e., to obtain relative displacements).

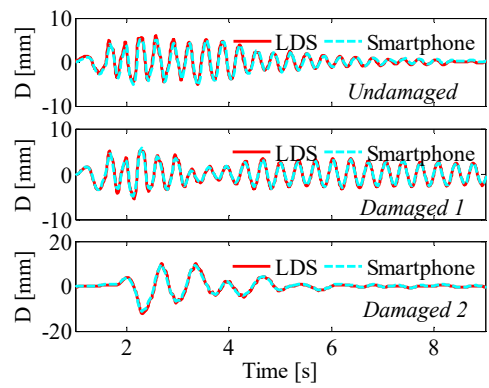

(a)

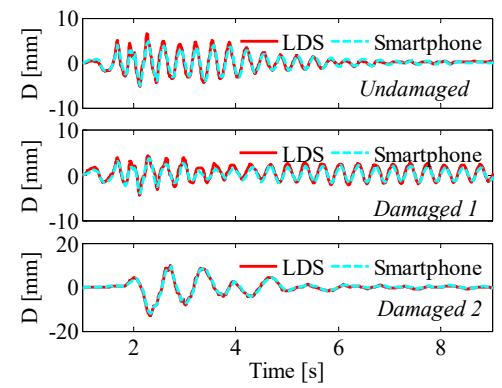

(b)

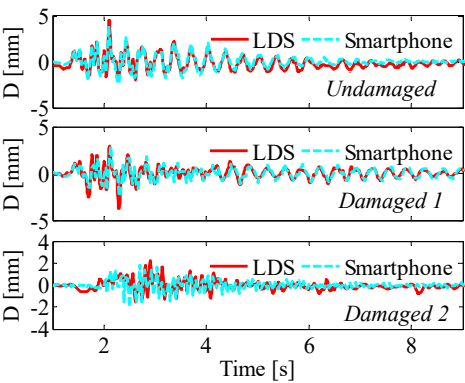

(c)

Figure 6. The displacement time history responses as collected by the LDS and smartphones, for the undamaged case and two damaged cases, were compared to show good agreement, except for the results from the third-floor damaged case. Representative results from the (a) first, (b) second, and (c) third floors were overlaid.

First, Figure 6 shows that the maximum displacement in the damaged case \#2 was larger than that for the undamaged and damaged case \#1 systems. The maximum displacements recorded for all stories, corresponding to the undamaged and damaged cases, are presented in Table 2. This result makes sense, where the change in displacement of damaged case \#1 was smaller than that of damaged case \#2, since the stiffness of the structure in damaged case \#2 was reduced significantly. Second, there is good agreement between both sets of displacement data, particularly for the first and second stories, as well as all measurements for the undamaged case and damaged case \#1. The displacement time history of damaged case \#1 was similar to that of the undamaged case, but the amplitude attenuation was slower, since column damage resulted in a reduction in stiffness.

Discrepancies were observed for the third story data relating to damaged case \#2 (i.e., the error of the maximum displacement recorded was $23.8 \%$, as shown in Table 2), which could have been due to two reasons. While the overall stiffness of the structure was reduced by removing the rigid beam in the first story, rigid beams remained installed at the top two floors. The increased compliance of the beam-column joints in the first floor resulted in larger displacements, thereby leading to little displacement in the third floor compared to the lower floor, which resulted in the low signal-noise ratio for the third story. It should also be noted that the LDS was mounted on a fairly rigid triangular support frame 
bolted to the shaking table and was also subjected to shaking. Despite assuming that the position of the LDS moved with the shaking of the table, in reality, the LDS was subjected to vibrations induced by shaking table excitations. This effect was more significant as the LDS was mounted higher, which meant that the third floor was most susceptible to this effect. Future tests will consider this limitation and investigate more reliable sensor instrumentation techniques.

Table 2. Maximum displacements as recorded by the laser displacement sensors and smartphones.

\begin{tabular}{ccccc}
\hline Damage Cases & Sensors & First Floor $(\mathbf{m m})$ & $\begin{array}{c}\text { Second Floor } \\
\mathbf{( m m})\end{array}$ & $\begin{array}{c}\text { Third Floor } \\
\mathbf{( m m})\end{array}$ \\
\hline \multirow{3}{*}{ Undamaged } & LDS & 5.904 & 6.433 & 4.534 \\
& Smartphone & 5.121 & 5.578 & 3.961 \\
& Error & $13.3 \%$ & $13.3 \%$ & $12.6 \%$ \\
Damaged \#1 & LDS & 5.453 & 4.439 & 2.976 \\
& Smartphone & 4.852 & 4.053 & 2.906 \\
Damaged \#2 & Error & $11.02 \%$ & $8.70 \%$ & $2.35 \%$ \\
& LDS & 11.81 & 12.85 & 1.919 \\
& Smartphone & 11.06 & 11.82 & 1.463 \\
& Error & $6.35 \%$ & $8.02 \%$ & $23.8 \%$ \\
\hline
\end{tabular}

As Table 2 shows, the maximum inter-story displacement for the undamaged case occurred in the second story. This behavior is atypical of shear structures, where the cause could be due to the complex beam-column joints and the use of the removable beams for this three-story steel frame. In addition, the maximum inter-story displacement errors were relatively high. The first reason is the influence of sampling rate, where the sampling rate of the LDS was $100 \mathrm{~Hz}$ versus $30 \mathrm{~Hz}$ for smartphones equipped with D-Viewer. The difference in sampling rates could have led to measurement errors. The second reason may be due to the limited performance of $D$-Viewer in which its accuracy was highly influenced by ambient lighting conditions, the target (i.e., laser spot), and installation method. On the other hand, the maximum inter-story displacements of the first and second stories corresponding to damaged case \#2 were much greater than those recorded for the undamaged system due to the presence of dampers and the removal of the rigid beam in the first floor. While some errors were observed (particularly for the third story in damaged case \#2), the difference between the smartphone and LDS were small, so the results validated that smartphones provided high quality data and could potentially be used for the monitoring of inter-story displacements.

\section{Damage Detection Results and Discussion}

\subsection{Wavelet Packet Analysis Background}

At present, many structural damage identification methods, based on vibration data, have been developed [55,56]. The wavelet packet analysis method is used in this paper. Wavelet packets are a generalization of orthonormal and compactly supported waves $[57,58]$. Pioneered by Coifman and Wickerhauser [59,60], wavelet packet analysis (WPA) methods were successfully used for data compression [61]. A detailed discussion of WPA is omitted due their widespread use, and the specifics of this technique could be found in, for example, Ding et al. [62].

According to Parseval's theorem, the energy in the time-domain is equal to that of the frequency-domain. When damage occurs, the energy corresponding to each frequency would be redistributed, and the structural response, $f$, of each frequency band would change. Here, $f$ can be decomposed to several individual frequency bands using WPA. The energy of $f$ for each frequency band can be used as a characteristic to describe 
damage $[63,64]$. After decomposing $f, 2^{i}$ sub-frequency bands will be obtained. The response, $f$, can be expressed as:

$$
f=\sum_{j=0}^{2^{i}-1} f_{i, j}=f_{i, 0}+f_{i, 1}+\cdots+f_{i, 2^{i}-1}\left(j=0,1,2, \cdots, 2^{i}-1\right)
$$

where $f_{i, j}$ are the component signals, and $i$ indicates the wavelet packet decomposition level. The number of terms of $j$ used refers to the order of WPA. Suppose that the lowest frequency is 0 , and the highest frequency is $\omega_{m}$, then the bandwidth of each frequency band is $\omega_{m} / 2^{i}$. The energy $\left(E_{i, j}\right)$ of $f_{i, j}$ for each frequency band can be computed by:

$$
E_{i, j}=\sum\left|f_{i, j}\right|^{2}
$$

In this study, a damage index based on the energy ratio variation difference (ERVD) was employed and was formulated as follows [65]:

$$
\begin{gathered}
I_{p}=\frac{E_{i, p}}{\sum_{j=0}^{\sum^{i}-1} E_{i, j} / 2^{i}} \\
E R V_{p}=\left|I_{p}-\hat{I}_{p}\right| \\
E R V D=\sqrt{\sum_{p=0}^{2^{i}-1} E R V D_{p}^{2}}=\sqrt{\sum_{p=0}^{2^{i}-1}\left(E R V_{p}-\overline{E R V_{p}}\right)^{2}}
\end{gathered}
$$

where $I_{p}$ is the ratio between $E_{i, j}$ and the mean energy of all frequency energies for the undamaged case, and $\hat{I}_{p}$ is the $I_{p}$ for the damaged case. $E R V$ is defined as the energy ratio variation, while $\overline{E R V}$ is the mean energy ratio variation.

\subsection{Wavelet Packet Decomposition of Acceleration Time Histories}

De-noising of acceleration results was achieved by decomposing the data using threeorder WPA with 'db20' (i.e., the Daubechies wavelet function with a length of 20) to obtain eight frequency bands. $I_{p}$ was computed using acceleration data as measured by the PAs and smartphones, and the results for the undamaged and two damaged cases are summarized in Figure 7. In order to compute ERVD for the undamaged case relative to another undamaged case, different datasets for which the pristine structure was subjected to the same earthquake excitation were used. Table 3 shows ERVD for the different cases and for each story. From Table 3, it can be seen that the mean ERVD for the undamaged case is less than that of damaged case \#1 and far less than that of damaged case \#2. This result means that damaged case \#2 was characterized by a larger energy ratio variation as compared to the undamaged system, and the damage of damaged case \#2 was more severe than that of damaged case \#1. Furthermore, the ERVD differences between the PAs and smartphones were small. These results demonstrated the feasibility of using smartphones, coupled with damage index methods such as ERVD, for damage detection. The objective of this section is to verify the feasibility of performing damage detection using smartphones, and the results proved it. Further research studies will focus on the selected WPT parameters, for example, the level of decomposition and wavelet mother for smartphone signals. 


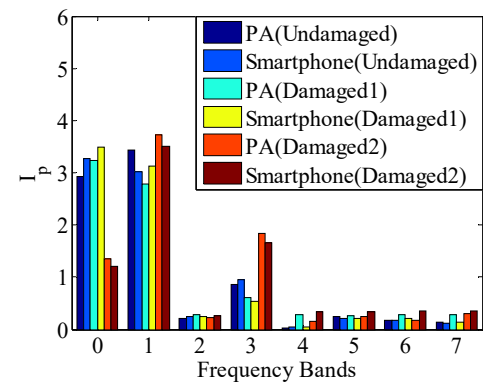

(a)

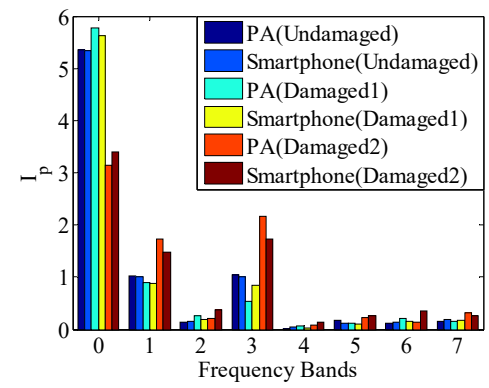

(b)

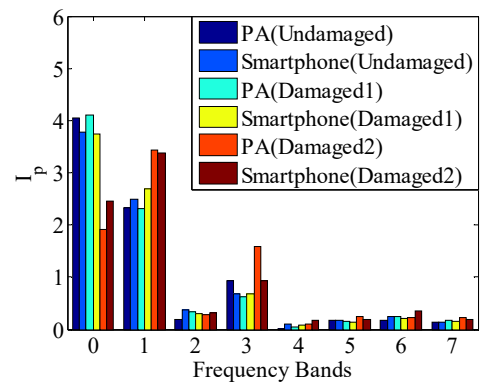

(c)

Figure 7. $I_{p}$ calculated for the (a) first, (b) second, and (c) third floors.

Table 3. ERVD for different cases and for each story.

\begin{tabular}{cccccc}
\hline Damage Cases & Sensors & First Story & Second Story & Third Story & Mean ERVD \\
\hline \multirow{2}{*}{ Undamaged } & Tethered PA & 0.1414 & 0.1403 & 0.0802 & 0.1206 \\
& Smartphone & 0.1464 & 0.1262 & 0.1592 & 0.1439 \\
Damaged\#1 & Tethered PA & 0.5189 & 0.4973 & 0.2564 & 0.4242 \\
& Smartphone & 0.3775 & 0.2608 & 0.1644 & 0.2676 \\
Damaged\#2 & Tethered PA & 1.411 & 2.636 & 2.260 & 2.102 \\
& Smartphone & 1.328 & 2.455 & 2.168 & 1.983 \\
\hline
\end{tabular}

\section{Displacement by Integration of Acceleration Data}

As mentioned earlier, displacement measurements are much more difficult to obtain than acceleration measurements. Therefore, the goal of this section is to validate the displacement measurement performance of smartphones. Validation of smartphone displacement measurements was performed by using integration techniques to compute displacement results from raw acceleration data. Data obtained from both PAs and smartphones, for both undamaged and damaged test cases, were used, and the results are compared. This was undertaken to further assess the quality of smartphone acceleration measurements.

\subsection{Acceleration Integration Methods}

A direct approach to acquire displacement from acceleration is to make use of the inherent relations between displacement, velocity, and acceleration in the time domain [66]. However, in cases in which the initial displacement is not 0 , and those in which the initial displacement is not considered, the estimated displacement response will result in critical errors. For example, the trend-term caused by zero-shift and noise will result in serious displacement drifts when applying time-domain integration [67]. Therefore, integration methods, such as integration in the frequency domain, are necessary for acquiring accurate displacement results. Specific methods of acceleration integration in the frequency domain were previously reported [68], and thus, are omitted in this paper. In general, it was shown that integration performed in the frequency domain is more sensitive to low frequencies $[69,70]$.

In practical applications, however, the acceleration response of civil structures typically always contains rich low-frequency components. During the pre- or post-processing response measurements, if the low-frequency cut-off is set too high, the actual response of the structure may be filtered inappropriately. Subsequent applications of integration in the frequency domain could lead to erroneous results, such as obtaining smaller displacements than those that actually occurred. In addition, the displacement time history result will show distinct oscillations. Therefore, selecting an appropriate cut-off frequency is critical for ensuring integration accuracy [21]. While the high-frequency cut-off could also influence the accuracy of integrated displacements to some extent, their impact is less severe, as mentioned earlier. Regardless, a challenge that remains is that the determination of the cut-off frequency is difficult simply because the actual response is unknown [71]. In the 
next section, the selection of cut-off frequency and its influence on integrated displacement results will be discussed.

\subsection{Experimental Investigation}

Using the acceleration time history data obtained from the shaking table tests presented in Section 3, inter-story displacements were computed via integration. In general, in order to obtain the inter-story displacements, inter-story acceleration should be used. This was obtained by subtracting the acceleration (at every instant of time) of the immediate lower story from that of the story being considered. For example, the first inter-story acceleration was calculated by subtracting the measured ground excitation from the acceleration time history, as recorded by the sensor mounted on the first story.

The cut-off frequency is defined as the frequency either above or below which the power output of a circuit, such as a line, amplifier, or electronic filter, has decreased to a predefined ratio of the power in the passband. Most frequently, this proportion is one half of the passband power, which is also referred to as the $3 \mathrm{~dB}$ point, since a drop of $3 \mathrm{~dB}$ corresponds to approximately half of the power.

Suppose that $f_{c 1}$ and $f_{c 2}$ are frequency components of the signal, then the magnitude transfer function of a bandpass filter with a lower $3 \mathrm{~dB}$ cut-off frequency of $f_{c 1}$ and $f_{1}$, and an upper $3 \mathrm{~dB}$ cut-off frequency of $f_{c 2}$ and $f_{2}$, is:

$$
\begin{gathered}
20 \log \left(\frac{f_{1}}{f_{c 1}}\right)=-3 \\
20 \log \left(\frac{f_{2}}{f_{c 2}}\right)=3
\end{gathered}
$$

In that regard, the lower and upper cut-off frequencies are related to $f_{c}$, where $f_{1} \approx$ $f_{1} \approx \sqrt{2} f_{c 1} / 2$ and $f_{2} \approx \sqrt{2} f_{c 2}$. During the inter-story displacement integration process, the center frequency needed to be determined first. Three bandwidths were selected to integrate the acceleration to observe the influence of the cut-off frequency. First, the first modal frequency of a structure was an important characteristic frequency component of the system and was thus taken as the center frequency for $f_{c 1}$ and $f_{c 2}$. Second, the first modal frequency was taken as $f_{c 1}$ to determine the low cut-off frequency, while the third modal frequency was taken as $f_{c 2}$ to determine the high cutoff frequency in order to include all modes in the integrated displacement. The first, second and third modal frequencies were taken as $f_{c 1}$ and $f_{c 2}$ to determine the low and high cut-off frequency, respectively. A comparison with the measured displacement was conducted to investigate the accuracy of these cut-off frequency selections. From Figures 5 and 6, it can be seen that the acceleration and displacement time histories of damaged case \#1 were similar to those of the undamaged case. Given this similarity, the undamaged and damaged case \#2 datasets, which have strong distinctions, were selected for this investigation.

\subsubsection{Undamaged Case}

From Table 1, it can be seen that the first, second, and third modal frequencies of the undamaged frame were found to be $3.182 \mathrm{~Hz}, 8.9 \mathrm{~Hz}$ and $12.6 \mathrm{~Hz}$. According to Equation (6), three bandwidths $(2.25 \mathrm{~Hz}, 4.5 \mathrm{~Hz}),(2.25 \mathrm{~Hz}, 17.82 \mathrm{~Hz})$ and $(6.692 \mathrm{~Hz}$, $17.82 \mathrm{~Hz}$ ) were determined for the examination of the integration performance. Figure 8 shows comparisons of integrated displacement (ID), using both the acceleration time history records obtained using PAs and smartphones, and the measured LDS inter-story displacements of the first story. From Figure $8 \mathrm{a}, \mathrm{b}$, it can be seen that the integrated displacement time histories were similar to the LDS measurements (i.e., when the $(2.25 \mathrm{~Hz}$, $4.5 \mathrm{~Hz})$ and $(2.25 \mathrm{~Hz}, 17.82 \mathrm{~Hz})$ cut-off frequencies were used). However, Figure $8 \mathrm{c}$ shows that the differences between IDs and the measurements were significant with the bandwidth of $(6.692 \mathrm{~Hz}, 17.82 \mathrm{~Hz})$. The bottom-most subplots of Figure 8 also show that the IDs obtained using tethered accelerometers versus smartphones are also very similar. 


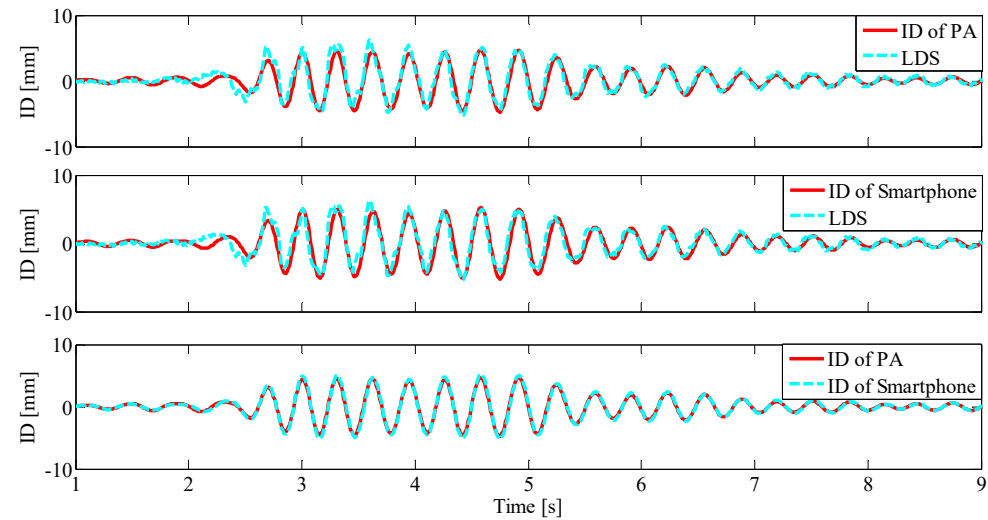

(a) Bandwidth of $(2.25 \mathrm{~Hz}, 4.5 \mathrm{~Hz})$

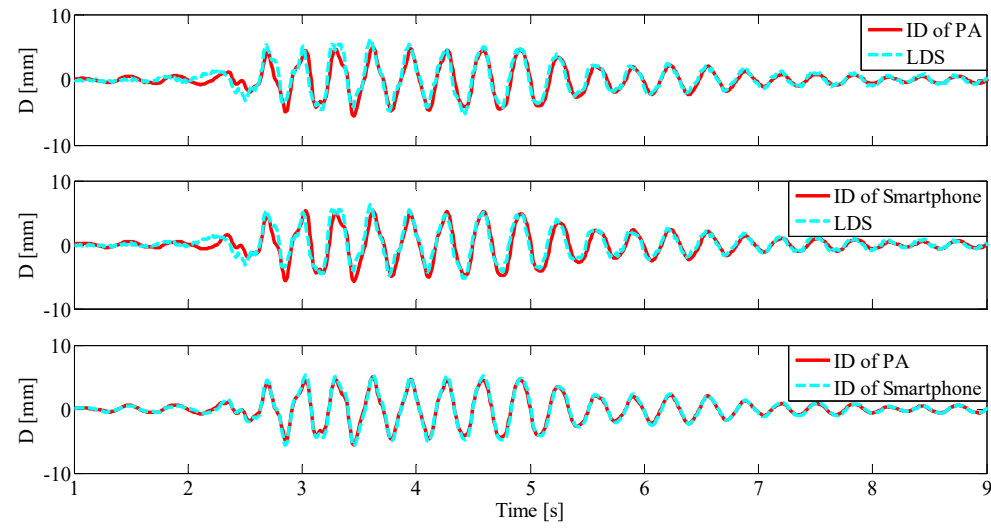

(b) Bandwidth of $(2.25 \mathrm{~Hz}, 17.82 \mathrm{~Hz})$

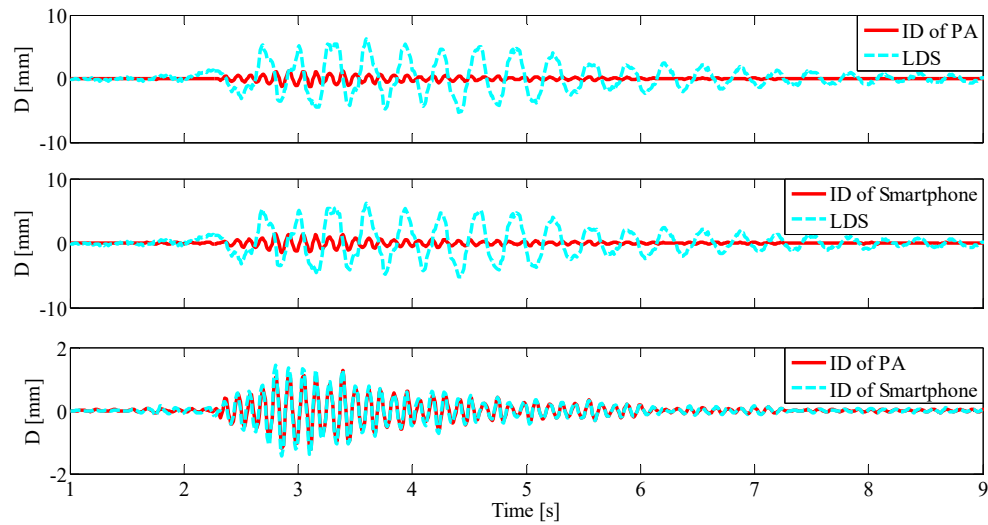

(c) Bandwidth of $(6.292 \mathrm{~Hz}, 17.82 \mathrm{~Hz})$

Figure 8. The comparisons between integrated and measured displacements of the first story (using data from PAs, LDS, and smartphones) for the undamaged case are shown.

To further quantify the errors, three parameters are proposed, namely, the crosscorrelation coefficient (CC), the mean maximum relative error (MMRE), and the sum of squares error (SSE). 
$\mathrm{CC}$ is used to describe the cross-correlation between the two results. MMRE examines how the positive and negative peaks compare with the measured displacement data and is computed using Equation (7):

$$
M M R E=\frac{1}{2}\left(\frac{|\max (x(t)-s(t))|}{|\max (s(t))|}+\frac{|\min (x(t)-s(t))|}{|\min (s(t))|}\right)
$$

where $x(t)$ is the integrated displacement, and $s(t)$ is the measured displacement. Since a comparison of only the peak value differences is insufficient for evaluating the accuracy of the integrated displacements, SSE is defined to describe the energy difference between the integrated and measured displacements.

$$
S S E=\left|\frac{\sum_{i=1}^{N}|x(i)|^{2}-\sum_{i=1}^{N}|s(i)|^{2}}{\sum_{i=1}^{N}|s(i)|^{2}}\right|
$$

where $x(i)$ and $s(i)$ are the displacement samples of $x(t)$ and $s(t)$, respectively, and $N$ is the number of samples or data points considered. The closer MMRE and SSE are to 0, the more accurate the results.

The results of error analysis are summarized in Table 4. Similar to before, the displacement reference was based on LDS measurements. In the rows of Table 4, CC, MMRE, and SSE correspond to the three error metrics defined earlier. This is followed by ' $\mathrm{S}$ ' or ' $\mathrm{PA}^{\prime}$ ', where ' $\mathrm{S}$ ' corresponds to data from the smartphone and ' $\mathrm{PA}^{\prime}$ for the tethered accelerometer. From Table 4, it can be seen that, when the low cut-off frequency was selected based on the first modal frequency of the test structure, and according to Equation (6), no matter what the high cut-off frequency was, the cross-correlation coefficient between the measured displacements and IDs was larger than 0.9 in the first and second stories, indicating strong correlation. It can also be seen from Table 4 that the result obtained with the low cut-off frequencies set to $2.25 \mathrm{~Hz}$ was, overall, better than when $6.292 \mathrm{~Hz}$ was used, which demonstrated the validity of using the first identified modal frequency as the low cut-off center frequency. Furthermore, the difference was not significant between $(2.25 \mathrm{~Hz}, 4.5 \mathrm{~Hz})$ and $(2.25 \mathrm{~Hz}, 17.82 \mathrm{~Hz})$. Thus, ID was sensitive to the low cut-off frequency but less sensitive to the high cut-off frequency. On the other hand, the CC was relatively low for the third story; this may have been due to problems associated with sensor instrumentation, which were mentioned earlier, that ultimately affected the accuracy of the LDS displacement measurements. Since the third-story LDS measurements were compromised, the discussions herein will omit that case. The results are presented in Table 4 for the sake of completeness.

Table 4. Error analysis of IDs versus LDS for the undamaged case.

\begin{tabular}{cccccccc}
\hline Story & Bandwidth & CC_S & CC_PA & MMRE_S & MMRE_PA & SSE_S & SSE_PA \\
\hline \multirow{3}{*}{ First story } & $(2.25,4.5)$ & 0.9159 & 0.9293 & 0.5048 & 0.5007 & 0.0112 & 0.1374 \\
& $(2.25,17.82)$ & 0.9150 & 0.9249 & 0.6233 & 0.5578 & 0.0409 & 0.1140 \\
& $(6.292,17.82)$ & 0.0611 & 0.0362 & 1.0876 & 1.0665 & 0.9741 & 0.9796 \\
Second story & $(2.25,4.5)$ & 0.9099 & 0.9256 & 0.4980 & 0.4810 & 0.0975 & 0.1037 \\
& $(2.25,17.82)$ & 0.8848 & 0.9057 & 0.5865 & 0.6093 & 0.0398 & 0.0626 \\
Third story & $(6.292,17.82)$ & 0.0249 & 0.0031 & 1.0133 & 1.0175 & 0.9524 & 0.9650 \\
& $(2.25,4.5)$ & 0.5795 & 0.7235 & 1.3305 & 1.0244 & 0.3778 & $2.93 \times 10^{-5}$ \\
& $(2.25,17.82)$ & 0.4864 & 0.6322 & 1.7785 & 1.3443 & 0.7571 & 0.3711 \\
\hline
\end{tabular}

Table 5 shows the comparison of IDs for the PA versus the smartphones, where it can be seen that the IDs coincide well with one another for all sets of cut-off frequency bands. Overall, these results confirm that the quality of smartphone acceleration measurements are sufficient for extracting inter-story displacements using the proposed technique. It 
should be mentioned, however, that the CC was relatively low for the third story (Table 5), and, similar to before, this may have been due to errors during testing and the use of an older iPhone model in the third story.

Table 5. Error comparison of PA versus smartphone for the undamaged case.

\begin{tabular}{ccccc}
\hline Story & Bandwidth & CC & MMRE_S & SSE_S \\
\hline \multirow{3}{*}{ First story } & $(2.25,4.5)$ & 0.9958 & 0.1414 & 0.1723 \\
& $(2.25,17.82)$ & 0.9950 & 0.1589 & 0.1748 \\
& $(6.292,17.82)$ & 0.9669 & 0.3344 & 0.2694 \\
Second story & $(2.25,4.5)$ & 0.9915 & 0.1410 & 0.0007 \\
& $(2.25,17.82)$ & 0.9875 & 0.2138 & 0.0243 \\
Third story & $(6.292,17.82)$ & 0.9443 & 0.3294 & 0.3614 \\
& $(2.25,4.5)$ & 0.8021 & 0.8275 & 0.3543 \\
& $(2.25,17.82)$ & 0.8221 & 0.5763 & 0.3335 \\
\hline
\end{tabular}

It was mentioned earlier that different models of smartphones sampled acceleration data at slightly different sampling rates, even though they were commanded to record at $100 \mathrm{~Hz}$ (i.e., a time step of $0.01 \mathrm{~s}$ ). The sampling rate of the iPhone 6 was $100 \mathrm{~Hz}$, that of the iPhone $5 \mathrm{~s}$ was $96 \mathrm{~Hz}$, and that of the iPhone $4 \mathrm{~s}$ was $109 \mathrm{~Hz}$. However, these sampling rates were average sampling rates for a set measurement period. To further investigate how each iPhone sampled acceleration data, $\sim 2 \mathrm{~s}$ of acceleration data are overlaid in Figure 9. It can be observed from Figure 9 that, overall, the stability of the iPhone 6 was best, except for a few data points; the stability of the iPhone $5 \mathrm{~s}$ and $4 \mathrm{~s}$ were comparatively worse, which can be observed as jumps in the measurement results shown in Figure 9. There are instances where the $0.01 \mathrm{~s}$ time step grew to over $0.05 \mathrm{~s}$. This was equivalent to missing four or five measurement points. This represents a flaw in the use of smartphones to obtain vibration data. To mitigate these issues, these tests suggest that choosing the newest version of smartphones for monitoring will likely yield the best performance, especially considering both hardware and software enhancements in the newer models. In order to mitigate the sampling rate differences between different iPhone models, the raw data were interpolated so that error analysis could be performed with respect to the LDS measurements. However, any variations in time step would have resulted in errors by virtue of relying on interpolation.

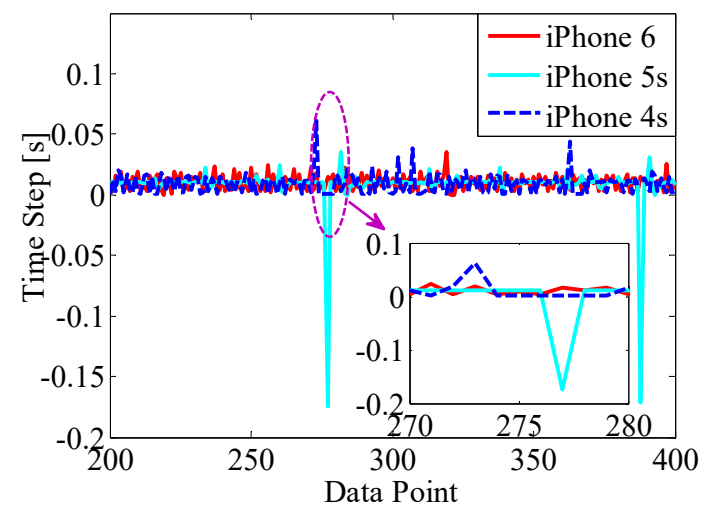

Figure 9. The time step between acceleration measurements as obtained by Orion-CC and the three different iPhone models show the relative stability of each system.

\subsubsection{Damaged Case}

Similar to Section 5.2.1, the same analyses were also performed using the test results of damaged case \#2. From Table 3, the first, second, and the third modal frequencies were identified as $1.545 \mathrm{~Hz}, 9.2 \mathrm{~Hz}$ and $12.2 \mathrm{~Hz}$. According to Equation (6), the cut-off 
frequency limits, $f_{1}$ and $f_{2}$, could be calculated. The three bandwidths were $(1.09 \mathrm{~Hz}$, $2.18 \mathrm{~Hz}),(1.09 \mathrm{~Hz}, 17.25 \mathrm{~Hz})$ and $(6.504 \mathrm{~Hz}, 17.25 \mathrm{~Hz})$. Figure 10 shows a comparison of the IDs for the first story, using data from PAs and smartphones, versus LDS measurements, as well as the ID comparisons of PAs versus smartphones. From the top two subplots in Figure 10a,b (i.e., the same low cut-off frequency but a different high cut-off frequency), it can be seen that some differences were observed for IDs versus the LDS measurements. In contrast, the bottom-most subplot of Figure 10a,b) shows that the IDs obtained using PA and smartphone acceleration data nearly coincided with one another.

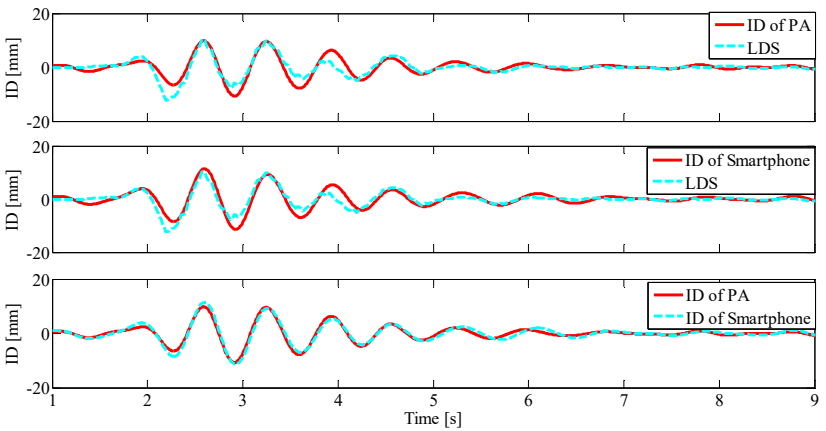

(a) Bandwidth of $(1.09 \mathrm{~Hz}, 2.18 \mathrm{~Hz})$

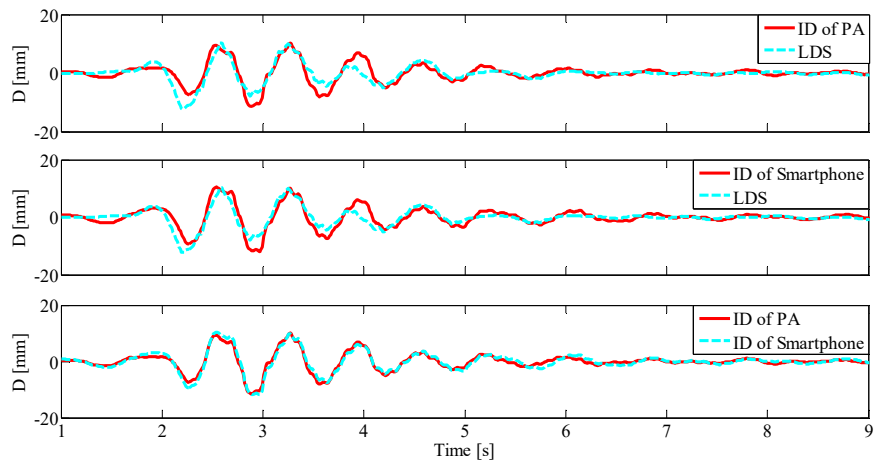

(b) Bandwidth of $(1.09 \mathrm{~Hz}, 17.25 \mathrm{~Hz})$
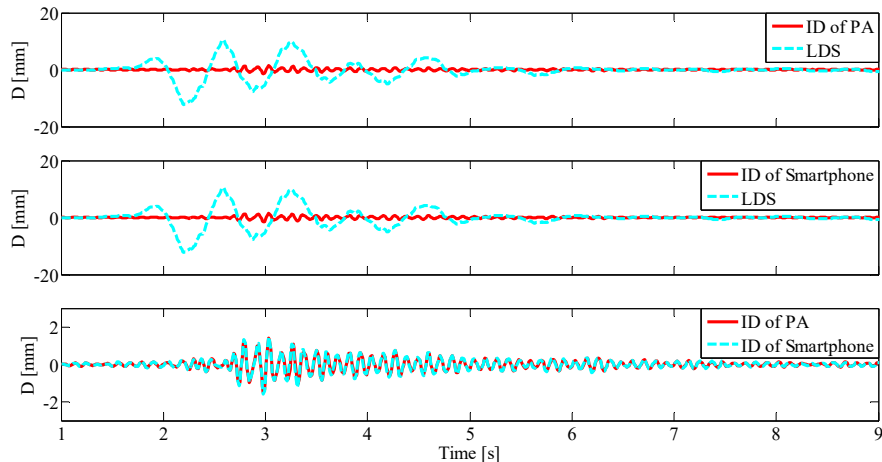

(c) Bandwidth of $(6.504 \mathrm{~Hz}, 17.25 \mathrm{~Hz})$

Figure 10. The comparisons between integrated and measured displacements of the first story (using data from PAs, LDS, and smartphones) for the damaged case are shown.

Figure 10c shows the significant error between IDs and measured displacements. These results illustrate that ID is sensitive to low cut-off frequencies, which again points to the importance of selecting the first modal frequency as the center frequency. These 
results also reveal that the IDs computed using PA and smartphone acceleration data for the damaged system were not as accurate as the IDs for the undamaged case, where strong non-linearity may have been the reason for this lower performance. On the other hand, the LDS measurements may contain some experimental errors, perhaps due to the vibration of the LDS support truss during shaking table excitations, which has been demonstrated before.

Error analyses were also performed by computing and comparing CC, MMRE, and SSE, similarly to the undamaged case. Table 6 summarizes the error analysis results, comparing IDs versus LDS measurements. From Table 6, it can be seen that the error analyses in the first and second stories yielded similar quantities as Table 4 for the undamaged case; however, this was not the case for the third story. The error appeared to be smaller when the second mode was taken as the center frequency. In this case, the rigid beam was removed to create damage for this scenario. The dampers affected the structures and led to large displacements in the first and second story and smaller displacements in the third story, which can be seen in Figure 6c. The response contained more high frequency content for the third story, and its vibration behavior was not the same as the lower stories due to severe damage introduced to the first story. Again, the third-story results are not considered due to errors experienced during testing but are shown here solely for the sake of completeness. It should be noted that, for the first and second stories, the CC values were all greater than 0.78 , which suggests that the correlation was satisfactory but not great.

Table 6. Error analysis of IDs versus LDS for the damaged case.

\begin{tabular}{cccccccc}
\hline Story & Bandwidth & CC_S & CC_PA & MMRE_S & MMRE_PA & SSE_S & SSE_PA \\
\hline \multirow{3}{*}{ First story } & $(1.09,2.18)$ & 0.8718 & 0.8461 & 0.5109 & 0.5671 & 0.2314 & 0.0794 \\
& $(1.09,17.25)$ & 0.8539 & 0.8261 & 0.5502 & 0.5904 & 0.2737 & 0.1191 \\
& $(6.504,17.25)$ & 0.0393 & 0.0331 & 1.0235 & 1.0235 & 0.9896 & 0.9907 \\
Second story & $(1.09,2.18)$ & 0.7946 & 0.8411 & 0.5278 & 0.4390 & 0.1724 & 0.3404 \\
& $(1.09,17.25)$ & 0.7889 & 0.8273 & 0.5577 & 0.4518 & 0.2000 & 0.2863 \\
Third story & $(6.292,17.25)$ & 0.0466 & 0.0531 & 0.9561 & 0.9626 & 0.9859 & 0.9894 \\
& $(1.09,2.18)$ & 0.1255 & 0.1258 & 2.0081 & 1.2036 & 9.2530 & 0.4096 \\
& $(1.09,17.25)$ & 0.2272 & 0.3341 & 2.2226 & 1.1585 & 10.859 & 1.5911 \\
\hline
\end{tabular}

Table 7 summarizes the error analyses results comparing PA versus smartphone performance for data corresponding to the damaged structure. The results are comparable to Table 5, where the first and second stories performed well. However, greater discrepancies were observed for the third story (as is evident from the low CC values in Table 7) for reasons already mentioned. Overall, from the results presented in Tables 4-7, it can be concluded that the quality of acceleration measurements, as recorded by smartphones, are comparable to those acquired by conventional tethered accelerometers.

Table 7. Error analysis of PA versus smartphone for the damaged case.

\begin{tabular}{ccccc}
\hline Story & Bandwidth & CC & MMRE & SSE \\
\hline \multirow{3}{*}{ First story } & $(1.09,2.18)$ & 0.9714 & 0.1869 & 0.1408 \\
& $(1.09,17.25)$ & 0.9715 & 0.1822 & 0.1382 \\
& $(6.504,17.25)$ & 0.9724 & 0.3374 & 0.1210 \\
Second story & $(1.09,2.18)$ & 0.9352 & 0.4653 & 0.7001 \\
& $(1.09,17.25)$ & 0.9337 & 0.4363 & 0.6813 \\
Third story & $(6.504,17.25)$ & 0.9330 & 0.4284 & 0.3260 \\
& $(1.09,2.18)$ & 0.6314 & 2.7805 & 6.2735 \\
& $(1.09,17.25)$ & 0.2051 & 1.5749 & 3.5765 \\
\hline
\end{tabular}




\section{Conclusions}

In this paper, shaking table tests of a three-story steel frame, instrumented with conventional transducers and smartphones equipped to measure acceleration and interstory displacement, were conducted. Smartphones preloaded with Orion-CC and D-Viewer were employed to enable these devices to record acceleration and displacement (i.e., using video recordings). After exciting the undamaged structure using the El-Centro earthquake ground motion record, damage was introduced to the system. Here, damaged case \#1 was introduced by reducing the column cross-sectional area, and damage case \#2 was introduced by removing a rigid beam in the first floor of the system to engage rotary dampers installed at the beam-column connections. First, this study compared smartphone acceleration and inter-story displacement measurements with data obtained using tethered accelerometers and laser displacement sensors. The acceleration response compared fairly well, as did the inter-story displacement measurements; however, more significant errors in inter-story displacements were observed for data corresponding to the third story, especially in damaged case \#2. This could have been due to experimental errors caused by vibrations of the LDS mounting frame, significant damage to the column-beam joint in the first story, measurement errors from smartphones, and the minor displacement in the third story. Second, wavelet packet analysis was employed for the analysis of acceleration data, and a damage index based on ERVD was computed for the different cases. The results demonstrated the feasibility of performing damage detection using smartphones. Last, to further validate the quality of smartphone measurements, inter-story displacement was computed by means of frequency-domain integration of the acceleration measurements. The cut-off frequency band was selected according to the first, second, and third modal frequencies identified for comparing the integration accuracies. The results showed that the integrated displacements compared well with the measured displacement when the low cut-off frequency was based on the first modal frequency. The quality of integrated displacements (i.e., using smartphone and conventional accelerometer data) compared well with one another.

Overall, this study demonstrated the feasibility of using smartphones for the dynamic monitoring of structural systems (e.g., frames) subjected to earthquake excitations. One advantage of using smartphones is that smartphones house a diverse suite of sensors in one compact form factor. While displacement and acceleration data were collected using different smartphones in this study, in principle, both apps could be installed on a single smartphone where collocated acceleration and displacement data could be acquired, which would be convenient. In contrast, conventional instrumentation strategies would require two separate sensors (as in the case of using an accelerometer and an LDS) to acquire these two different sets of data. More realistic experiments for the monitoring of buildings' responses will be conducted in the future.

Author Contributions: Conceptualization, X.Z.; methodology, R.H.; software, R.H.; validation, R.H.; formal analysis, R.H.; investigation, X.Z.; resources, X.Z.; data curation, R.H.; writing-original draft preparation, R.H.; writing —review and editing, R.H. and X.Z.; visualization, R.H.; supervision, R.H.; project administration, X.Z.; funding acquisition, R.H. All authors have read and agreed to the published version of the manuscript.

Funding: This research was funded by the High Level Talents Scientific Research Startup Project of North China University of Water Resources and Electric Power (201811036), Key R \& D and promotion projects of Henan Province (212102310934) and the Open Fund of the State Key Laboratory of Coastal and Offshore Engineering of Dalian University of Technology (LP1806).

Institutional Review Board Statement: Not applicable.

Informed Consent Statement: Not applicable.

Data Availability Statement: Some or all data that support the findings of this study are available from the corresponding author upon reasonable request.

Conflicts of Interest: The authors declare no conflict of interest. 


\section{References}

1. Comartin, C.; Brvez, S.; Naeim, F.; Greene, M.; Blondet, M.; Cherry, S.; D'Ayala, D.; Farsi, M.; Jain, S.K.; Pantelic, J.; et al. A challenge to earthquake engineering professionals. Earthq. Spectra 2004, 20, 1049-1056. [CrossRef]

2. Takewaki, I.; Murakami, S.; Fujita, K.; Yoshitomi, S.; Tsuji, M. The 2011 off the Pacific coast of Tohoku earthquake and response of high-rise buildings under long-period ground motions. Soil Dyn. Earthq. Eng. 2011, 31, 1511-1528. [CrossRef]

3. Reyners, M. Lessons from the destructive Mw 6.3 Christchurch, New Zealand, Earthquake. Seismol. Res. Lett. 2011, 82, 371-372. [CrossRef]

4. Wilkison, S.; Grant, D.; Williams, E.; Paganoni, S.; Fraser, S.; Boon, D.; Mason, A.; Free, M. Observations and implications of damage from the magnitude Mw 6.3 Christchurch, New Zealand earthquake of 22 February 2011. Bull. Earthq. Eng. 2013, 11, 107-140. [CrossRef]

5. Lu, X.; Bengtsson, L.; Holme, P. Predictability of population displacement after the 2010 Haiti earthquake. Proc. Natl. Acad. Sci. USA 2012, 109, 11576-11581. [CrossRef]

6. Li, H.; Xiao, S.; Huo, L. Damage investigation and analysis of engineering structures in the Wenchuan earthquake. J. Build Struct. 2008, 29, 10-19. (In Chinese)

7. Guéguen, P.; Michel, C.; LeCorre, L. A simplified approach for vulnerability assessment in moderate-to-low seismic hazard regions: Application to Grenoble (France). Bull. Earthq. Eng. 2007, 5, 467-490. [CrossRef]

8. Ou, J.; Li, H. Structural Health Monitoring in mainland China: Review and Future Trend. Struct. Health Monit. 2010, 9, 219-231.

9. Zou, Y.; Tong, L.; Steven, G.P. Vibration-based model-dependent damage (delamination) identification and health Monitoring for composite structures-a review. J. Sound Vib. 2000, 230, 357-378. [CrossRef]

10. Peeters, B.; De Roeck, G. Stochastic System Identification for Operational Modal Analysis: A Review. J. Dyn. Syst. Trans. ASME 2001, 123, 659-667. [CrossRef]

11. Shih, C.Y.; Tsuei, Y.G.; Allemang, R.J.; Brown, D.L. Complex mode indication function and its application to spatial domain parameter estimation. Mech. Syst. Signal Process. 1988, 2, 367-377. [CrossRef]

12. Allemang, R.J.; Brown, D.L.; Fladung, W. Modal parameter estimation: A unified matrix polynomial approach. Proc. SPIE Int. Soc. Opt. Eng. 1994, 2251, 501-514.

13. Akaike, H. A New Look at the Statistical Model Identification. IEEE Trans. Automat. Control 1974, 19, 667-674. [CrossRef]

14. Van Overschee, P.; De Moor, B. Subspace algorithm for the stochastic identification problem. Automatica 1993, 29, 649-660. [CrossRef]

15. Hearn, G.; Testa, R.B. Modal Analysis for Damage Detection in Structures. J. Struct. Eng. 1991, 117, 3042-3063. [CrossRef]

16. Lam, H.F.; Hu, J.; Yang, J.H. Bayesian operational modal analysis and Markov chain Monte Carlo-based model updating of a factory building. Eng. Struct. 2017, 132, 314-336. [CrossRef]

17. Worden, K.; Green, P.L. A machine learning approach to nonlinear modal analysis. Mech. Syst. Signal Process. 2017, 84, 34-53. [CrossRef]

18. Mirshafiei, F.; Mirshafiei, M.; McClure, G. A new three-dimensional seismic assessment method (3D-SAM) for buildings based on experimental modal analysis. Comput. Struct. 2017, 180, 125-137. [CrossRef]

19. Smyth, A.; Wu, M. Multi-rate Kalman filtering for the data fusion of displacement and acceleration response measurements in dynamic system monitoring. Mech. Syst. Signal Process. 2007, 21, 706-723. [CrossRef]

20. Gindy, M.; Vaccaro, R.; Nassif, H.; Velde, J. A state-space approach for deriving bridge displacement from acceleration. ComputerAided Civ. Inf. 2008, 23, 281-290. [CrossRef]

21. Thong, Y.K.; Woolfson, M.S.; Crowe, J.A. Hayes-Gill BR and Jones DA. Numerical dubble integration of acceleration measurements in noise. Measurement 2004, 36, 73-92. [CrossRef]

22. Hsieh, K.H.; Halling, M.W.; Barr, P.J. Overview of vibrational structural health monitoring with representative case studies. J. Bridge Eng. 2006, 11, 707-715. [CrossRef]

23. Fan, W.; Qiao, P. Vibration-based damage identification methods: A review and comprehensive study. Struct. Health Monit. 2010, 10, 83-111. [CrossRef]

24. Brownjohn, J.M.W. Structural health monitoring of civil infrastructure. Philos. Trans. R. Soc. A 2007, 365, 589-622. [CrossRef] [PubMed]

25. Kim, S.; Pakzad, S.; Culler, D.; Demmel, J.; Fenves, G.; Glaser, S.; Turon, M. Health monitoring of civil infrastructures using wireless sensor networks. In Proceedings of the 6th IEEE International Symposium on Information Processing Sensor Networks, Cambridge, MA, USA, 25-27 April 2007; pp. 254-263.

26. Lynch, J.P.; Loh, K.J. A Summary Review of Wireless Sensors and Sensors networks for Structural Health Monitoring. Shock Vib. Dig. 2006, 38, 91-130. [CrossRef]

27. Lynch, J.P.; Wang, Y.; Loh, K.J.; Yi, J.-H.; Yun, C.-B. Performance Monitoring of the Geumdang Bridge using a Dense Network of High-Resolution Wireless Sensors. Smart Mater. Struct. 2006, 15, 1561-1575. [CrossRef]

28. Bao, Y.; Yu, Y.; Li, H.; Mao, X.; Jiao, W.; Zou, Z.; Ou, J. Compressive sensing-based lost data recovery of fast-moving wireless sensing for structural health monitoring. Struct. Control Health Monit. 2015, 22, 433-448. [CrossRef]

29. Bao, Y.; Wu, F. A mobile wireless sensor-based structural health monitoring technique. In Proceedings of the Civil Structural Health Monitoring Workshop (CSHM-4), Berlin, Germany, 6-8 November 2012. 
30. Zhao, X.; Han, R.; Yu, Y.; Hu, W.; Jiao, D.; Mao, X.; Li, M.; Ou, J. Smartphone-based mobile testing technique for quick bridge cable-force measurement. J. Bridge Eng. 2017, 22, 06016012. [CrossRef]

31. Lau, S.L.; König, I.; David, K.; Parandian, B.; Carius-Düssel, C.; Schultz, M. Supporting patient monitoring using activity recognition with a smartphone. In Proceedings of the 7th IEEE International Symposium on Wireless Communication Systems (ISWCS), York, UK, 19-22 September 2010; pp. 810-814.

32. Lau, S.L.; David, K. Movement recognition using the accelerometer in smartphones. In Proceedings of the IEEE Future Network and Mobile Summit, Florence, Italy, 16-18 June 2010; pp. 1-9.

33. Li, W.; Lin, Y.; Ye, S. Shock Detection with smart mobile phone and its application in car accident self-rescue. Comput. Eng. 2011, $37,245-247$.

34. Yu, Y.; Zhao, X.; Ou, J. A new idea: Mobile Structural Health Monitoring using Smartphones. In Proceedings of the IEEE Third International Conference on Intelligent Control and Information Processing, Dalian, China, 15-17 June 2012; pp. 714-716.

35. Höpfner, H.; Morgenthal, G.; Schirmer, M.; Naujoks, M.; Halang, C. On measuring Mechanical oscillations using smartphone sensors-possibilities and limitation. ACM SIGMOBILE Mob. Comput. Commun. Rev. 2013, 17, 29-41. [CrossRef]

36. Morgenthal, G.; Höpfner, H. The application of smartphones to measuring transient structural displacements. J. Civ. Struct. Health Monit. 2012, 2, 149-161. [CrossRef]

37. Kotsakos, D.; Sakkos, P.; Kalogeraki, V.; Gunopulos, D. SmartMonitor: Using Smart Devices to Perform Structural Health Monitoring. In Proceedings of the VLDB Endowment, Riva del Garda, Trento, Italy, 26-30 August 2013; Volume 6, pp. 1282-1285.

38. Reilly, J.; Dashti, S.; Ervasti, M.; Bray, J.D.; Glaster, S.D.; Bayen, A.M. Mobile phones as seismologic sensors: Automating data extraction for the iShake system. IEEE Trans. Autom. Sci. Eng. 2013, 10, 242-250. [CrossRef]

39. Sharma, A.; Gupta, D. Smartphone as a real-time and participatory data collection tool for civil engineers. Int. J. Mod. Comput. Sci. 2014, 2, 22-27.

40. Cimellaro, G.P.; Scura, G.; Renschler, C.S.; Reinhorn, A.M.; Kim, H.U. Rapid building damage assessment system using mobile phone technology. Earthq. Eng. Eng. Vib. 2014, 13, 519-533. [CrossRef]

41. Yu, Y.; Han, R.; Zhao, X.; Mao, X.; Hu, W.; Jiao, D.; Li, M.; Ou, J. Initial validation of Mobile-Structural Health Monitoring Method Using Smartphones. Int. J. Distrib. Sens. Netw. 2015, 11, 274391. [CrossRef]

42. Feng, M.; Fukuda, Y.; Mizuta, M.; Ozer, E. Citizen Sensors for SHM: Use of accelerometer data from smartphones. Sensors 2015, 15, 2980-2998. [CrossRef]

43. Ozer, E.; Feng, M.Q.; Feng, D. Citizen Sensors for SHM: Towards a crowdsourcing platform. Sensors 2015, 15, 14591-14614. [CrossRef]

44. Min, J.; Gelo, N.J.; Jo, H. Real-time image processing for non-contact monitoring of dynamic displacements using smartphone technologies. Proc. SPIE Sens. Smart Struct. Technol. Civ. Mech. Aerosp. Syst. 2016, 9803, 98031B.

45. Oraczewski, T.; Staszewski, W.J. Nonlinear acoustics for structural health monitoring using mobile, wireless and smartphonebased transducer platform. J. Intel. Mat. Syst. Str. 2015, 27, 786-796. [CrossRef]

46. Ozer, E.; Feng, M.Q. Synthesizing spatiotemporally sparse smartphone sensor data for bridge modal identification. Smart Mater. Struct. 2016, 25, 085007. [CrossRef]

47. Ozer, E.; Feng, M.Q. Direction-sensitive smart monitoring of structures using heterogeneous smartphone sensor data and coordinate system transformation. Smart Mater. Struct. 2017, 26, 045026. [CrossRef]

48. Tan, H.; Chen, J. Experiment verification of mobile phones for vibration measurement. In Proceedings of the 7th International Conference on Structural Health Monitoring of Intelligent Infrastructure, Torino, Italy, 1-3 July 2015.

49. Han, R.; Zhao, X.; Yu, Y.; Guan, Q.; Hu, W.; Li, M. A Cyber-Physical System for Girder Hoisting Monitoring Based on Smartphones. Sensors 2016, 16, 1048. [CrossRef]

50. Han, R.; Zhao, X.; Yu, Y.; Guan, Q.; Peng, D.; Li, M.; Ou, J. Emergency Communication and Quick Seismic Damage Investigation Based on Smartphones. Adv. Mater. Sci. Eng. 2016, 2016, 7456182. [CrossRef]

51. Zhao, X.; Ri, K.; Han, R.; Yu, Y.; Li, M.; Ou, J. Experimental research on quick structural health monitoring technique for bridges using smartphone. Adv. Mater. Sci. Eng. 2016, 2016, 1871230. [CrossRef]

52. Zhao, X.; Han, R.; Ding, Y.; Yu, Y.; Guan, Q.; Hu, W.; Li, M.; Ou, J. Portable and convenient cable force measurement using smartphone. J. Civ. Struct. Health Monit. 2015, 5, 481-491. [CrossRef]

53. Zhao, X.; Liu, H.; Yu, Y.; Zhu, Q.; Hu, W.; Li, M.; Ou, J. Displacement Monitoring Technique Using a Smartphone Based on the Laser Projection-Sensing Method. Sens. Actuators A Phys. 2016, 246, 35-47. [CrossRef]

54. Xie, B.; Li, J.; Zhao, X. Research on Damage Detection of a 3D Steel Frame Model Using Smartphones. Sensors 2019, $19,745$. [CrossRef] [PubMed]

55. Chen, Z.; Yu, L. A new structural damage detection strategy of Hybrid PSO with Monte Carlo simulations and Experimental verifications. Measurement 2018, 122, 658-669. [CrossRef]

56. Huang, M.; Gul, M.; Zhu, H.P. Vibration-Based Structural Damage Identification under Varying Temperature Effects. J. Aerosp. Eng. 2018, 31, 04018014. [CrossRef]

57. Mallat, S. A theory for multiresolution signal decomposition: The wavelet representation. IEEE Trans. Pattern Anal. 1989, 11, 674-693. [CrossRef]

58. Daubechies, I. Orthonormal bases of compactly supported wavelets. Commun. Pure Appl. Math. 1988, 41, 909-996. [CrossRef]

59. Coifman, R.R.; Meyer, Y. Orthonormal Wave Packet Bases; Technical report; Yale University: New Haven, CT, USA, 1990; preprint. 
60. Wickerhauser, M.V. Best-adapted wavelet packet bases. Daubechies 1993, 93, 155-171.

61. Coifman, R.R.; Wickerhauser, M.V. Entropy-based algorithms for best basis selection. IEEE Trans. Inform. Theory 1992, 38, 713-718. [CrossRef]

62. Ding, Y.; Li, A.; Miao, C. Theoretical research on structural damage alarming of long-span bridges using wavelet packet analysis. J. Southeast Univ. (Engl. Ed.) 2005, 21, 459-462.

63. Sun, Z.; Chang, C.C. Structural damage assessment based on wavelet packet transform. J. Struct. Eng. 2002, 128, 1354-1361. [CrossRef]

64. Ding, Y.; Li, A.; Miao, C. Investigation on the structural damage alarming method based on wavelet packet energy spectrum. Eng. Mech. 2006, 23, 42-48. (In Chinese)

65. Ding, Y.; Li, A.; Liu, T. A study on WPT-based structural damage alarming of the ASCE benchmark experiments. Adv. Struct. Eng. 2008, 11, 121-127. [CrossRef]

66. Yang, J.; Li, J.B.; Lin, G. A simple approach to integration of acceleration data for dynamic soil-structure interaction analysis. Soil Dyn. Earthq. Eng. 2006, 26, 725-734. [CrossRef]

67. Trifunac, M.D.; Lee, V.W. A note on the accuracy of computed ground displacements from strong-motion accelerograms. Bull. Seismol. Soc. Am. 1974, 64, 1209-1219. [CrossRef]

68. Han, S. Retrieving the time history of displacement from measured acceleration signal. KSME Int. J. 2003, 17, 197-206. [CrossRef]

69. Newland, D.E. An Introduction to Random Vibrations, Spectral \& Wavelet Analysis; Courier Corporation: North Chelmsford, MA, USA, 2012.

70. Han, S.; Lee, J.-B. Analysis of errors in the conversion of acceleration into displacement. In Proceedings of the 19th IMC, Cerkno, Slovenia, 20-23 September 2001.

71. Park, K.T.; Kim, S.H.; Park, H.S.; Lee, K.W. The determination of bridge displacement using measured acceleration. Eng. Struct. 2005, 27, 371-378. [CrossRef] 